\title{
The Vibration Impact Determination of the Helicopter Structural Components
}

\author{
Zeinab Khaksar ${ }^{1}$, Sreenatha Anavatti ${ }^{1}$, Krishna Shankar $^{1}$, Alessandro Ceruti ${ }^{2}$ and Heath Pratt ${ }^{1}$ \\ ${ }^{1}$ University of New South Wales, the School of Engineering and Information Technology, Canberra, Australia \\ ${ }^{2}$ University of Bologna, the School of Engineering, Bologna, Italy
}

\begin{abstract}
This paper presents the determination of the vibration impact of the helicopter structural components and skin repairs in terms of frequency characteristics. To address this issue, a 3D Finite Element Method (FEM) model of 349 Gazelle helicopter has been developed in ABAQUS and the frequency analysis is conducted. The results on the natural frequencies of the full structure reasonably match with the literature giving confidence in the baseline model. The main advantage of this FEM model is that, it can be used to predict the natural frequencies of the full structure, precisely. In addition, the material properties and conditions of the components can be updated based on the applied conditions during the repair and maintenance period. Thus, the model gives a comprehensive design tool for analysing the frequencies of the helicopter with differing components. The effective variations in the frequency changes due to repair are predicted numerically. The discussion of these results helps in developing leads to improved selection of replacement materials and their properties.
\end{abstract}

\section{Introduction}

One of the critical facts about the rotorcraft is that it has more complexity in both design and maintenance phases in comparison with the fixed-wing aircraft [1], [2].This is due to the purpose for which the rotorcraft has been inherently designed, for example violent, aggressive and rescue operations [3].

One of the most significant barriers on the development of the rotorcraft is the vibration which decelerates the advances in reliability, safety, occupant's comfort and increasing the maximum forward speed [4]. Moreover, the vibration in helicopters makes difficulties in reading the instruments, weapon operations, depreciation and failure in structural and non-structural components. Therefore, helicopters need to be monitored periodically and faulty components have to be replaced with the new ones [5]. By changing the faulty component, especially structural components focused in this research; with a new one (which could not be exactly the same as its original counterpart) there will be changes in the vibration characteristics of the system.

By 1990s, the vibration had not been considered in design phase of a helicopter, but some passive approach to capture it [5]. Nowadays, in order to minimize the costs, the vibration is being taken into account at design stage [6]. With this aim, there is a need to evaluate the vibration primarily. Therefore, obtaining a model of the structure as precise as possible, an aerodynamic model to simulate forces acting on the main rotor head, and the coupling between the fuselage and the main rotor are completely essential [7]. In this research, the impact of structural components on free vibration of the helicopter will be determined. During repair and maintenance of a helicopter, it is necessary to fix the cracks and damages on the fuselage or on the helicopter skin. But making new patches on the helicopter skin will lead to changes in vibration characteristics of the helicopter structure. This paper intends to determine the vibration impact of the helicopter structural components and skin repairs in terms of frequency characteristics.

\subsection{The structural model of the helicopter}

Yeo and Chopra (2001) consider the Finite Element Method (FEM) modelling as the first step of systematic modelling and analysis technique of the helicopter. In their research, the efforts of four helicopter companies (Bell, Boeing, the former McDonnell Douglas and Sirkorsky) to develop FEM models of the airframe and running their ground test, has been summarized. At the first they started with an FEM model of $\mathrm{AH}-1 \mathrm{G}$ helicopter which has 15 degrees of freedom (DoF), and totally is made of 39 elastic beam elements. In the mid1970s, they developed a 3D FEM model of that helicopter in NASTRAN software which consisted of 2965 elements including rods, bars, scalar springs, etc. which brought structural parts into modelling.

Gmurczyk et al. (2011) indicated that due to the complexity of rotorcraft structure, the FEM model should be developed in a hierarchy manner. They modelled the structure components of Mil Mi-24 like stringers and 
frames using bar and beams and then assigned the material properties to them, but about other structural components which does not have a great role in transferring the loads they considered their weights. Since the computer model of that helicopter was not available, a photogrammetric measurement was done and a model of fuselage with 3920 points was received. Based on the geometrical model, an FEM model of Mi-24 with 30000 elements was created in MSC.Patran. [8]. In a similar research done by Annett and Polanco (2010), an integrated FEM analysis of MD-500 was investigated. In a hierarchical approach, in the same manner of automotive industry which models the whole car system, its seats and even the occupants, the whole helicopter structure, the seats and pilots were modelled [9].

In another research carried under a cooperation between National aeronautics and space administration (NASA) and French ministry of defence, the vibration characteristics of a French helicopter called SA349/2 Gazelle was determined. In this NASA report the free and forced vibration of that helicopter was analysed and the relations between the main rotor frequency, fuselage vibration and the vibration at the pilot's seat were demonstrated. In this research two FEM models are developed with the same basic bars, beams, quadrangles and triangles. The updated model included 10 substructures, the total number of 730 nodes and 1063 elements. Also 51 concentrated masses are considered in order to simulate the overall weight of the helicopter [7].

There are two significant points on the presented literature. The first one is the extracting of the helicopter geometry through 3D photogrammetric technique [8] [9], modelling the helicopter by CAM/CAD method and finally producing the FEM model, which is quite expensive, needs especial instruments that can only be provided by giant industries or big research centres with huge budgets. The second point is about those FEM models created through elastic beam elements. The definite numbers of points connected through elastic beams do not model the real shape, cross sections and properties of the structural components precisely.

This paper describes the structural modelling of the helicopter and the effective variations in frequency changes due to repair through the methodology is described in section 2. The numerical prediction of natural frequencies for the basic and full structure and repaired structure are summarized in section 3 . The paper concludes in section 4 .

\section{Methodology}

The following paragraphs discuss the development of the 3D ABAQUS model for the 349 Gazelle helicopter. The characteristics of 349 Gazelle helicopter are summarized in Table 1.

Table 1. 349 gazelle characteristics

\begin{tabular}{|l|l|}
\hline Rotor radius $(\mathrm{m})$ & 5.25 \\
\hline Number of blades & 3 \\
\hline Rotor solidity & 0.0637 \\
\hline Design aircraft mass $(\mathrm{kg})$ & 2000 \\
\hline $\begin{array}{l}\text { Design main rotor rotational } \\
\text { speed (rpm) }\end{array}$ & 387 \\
\hline
\end{tabular}

Some steps have been taken towards simplifying the modelling in ABAQUS software. The first step is extracting the basic geometry of the Gazelle helicopter and generating the basic structure of the helicopter including the bulkheads, main cantilever beams, tail boom ribs and the tail boom skin which connects all the ribs together. Also, the curved beams are used to build the cockpit top section and the ones in which the windscreen part (forward cockpit section) sits are designed. In this way a precise model of basic frame with regards to the material properties and the cross sections is established. The need to precise modelling of the basic frame or the basic structure is that it contributes to helicopter stiffness characteristics.

The second step is to add the secondary structural components that have a critical role in the vibration characteristics of the model. So, the fuselage skin, the cabin floor, the windscreen glass and doors are created with their assigned properties and attached to the model.

In the next step, the weight of the non-structural components including main rotor head, tail rotor head, gearboxes, engine, fuel tank, landing skid, swash plate, propulsion subsystem, flight boosted control and flight manual control have been calculated and added to certain points of the model as lumped mass. These weights have been calculated based on the formula [Boeing Vertol, Research and Technology Laboratories (RTL) of the US army] available for "up to $12,000 \mathrm{lb}$ gross weight class" [10].

During the damage repair, it is normal to fix the cracks by patching the particular part of the skin with an equivalent skin. In this study, we have looked at the skin patch of size $20 * 20 \mathrm{~cm}$ at the helicopter undercarriage. Variations in the density of the skin material are used to study the frequency variations. The material properties and the considered scenarios for the patched plate are as shown in Table 2 and Table 3 respectively.

Table 2. Material characteristics of the designed model in ABAQUS

\begin{tabular}{|l|l|l|l|}
\hline Material & Density $(\mathrm{kg} / \mathrm{m} 3)$ & Poisson's ratio & Young's modulus $(\mathrm{GPa})$ \\
\hline Aluminium 7075 & 2810 & 0.33 & 71.7 \\
\hline Plexiglass & 1162.5 & 0.35 & 2.4 \\
\hline
\end{tabular}

Table 3. Scenarios for changing the density of the patched plate

\begin{tabular}{|c|c|c|c|c|c|c|c|c|c|c|}
\cline { 2 - 11 } \multicolumn{1}{c|}{} & $+10 \%$ & $+20 \%$ & $+30 \%$ & $+40 \%$ & $+50 \%$ & $-10 \%$ & $-20 \%$ & $-30 \%$ & $-40 \%$ & $-50 \%$ \\
\hline Density & 3091 & 3372 & 3653 & 3934 & 4215 & 2529 & 2248 & 1967 & 1686 & 1405 \\
\hline
\end{tabular}




\section{Results and discussions}

The basic structure modelled and meshed in ABAQUS, with total number of 12826 elements, 24002 nodes, and the total weight of $251.97 \mathrm{~kg}$ is shown in Fig. 1.

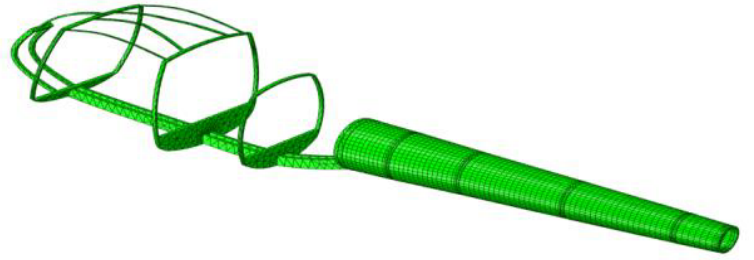

Figure 1. Basic structure of gazelle helicopter developed in ABAQUS software
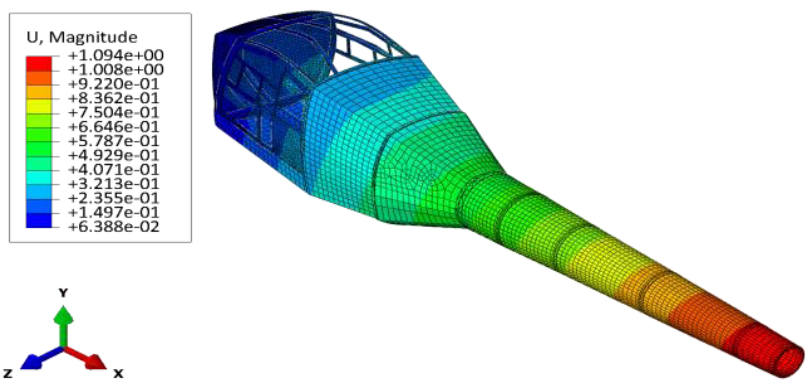

Figure 2. Completed model of gazelle helicopter at its first mode

A free vibration analysis was carried out to extract the natural frequencies of the basic frame up to its 40 modes, which is $76.4 \mathrm{~Hz}$. To summarize, the results have been reported by mode number up to 20 which is around 37.1 $\mathrm{Hz}$, as shown in Table IV (the second column). As it can be seen from the results, the first six modes are coupled rigid modes. The other structural parts of the helicopter including the fuselage, the doors, the windscreen glass, and floors are added to the model to monitor the frequency changes due to their addition. The completed model with the total mass of $375.45 \mathrm{~kg}$ at its first mode is shown in Fig. 2.

Table 4. Natural frequencies of the basic frame (the second column) and the full structure (the third column)

\begin{tabular}{|c|c|c|}
\hline Mode & $\begin{array}{c}\text { The frequency of } \\
\text { basic frame (Hz) }\end{array}$ & $\begin{array}{c}\text { The frequency } \\
\text { of full structure } \\
(\mathrm{Hz})\end{array}$ \\
\hline $1,2,3,4,5,6$ & 0.0 & 0.0 \\
\hline 7 & 8.2 & 3.4 \\
\hline 8 & 9.2 & 4.1 \\
\hline 9 & 11.2 & 9.1 \\
\hline 10 & 14.1 & 9.9 \\
\hline 11 & 14.8 & 10.5 \\
\hline 12 & 20.52 & 14.1 \\
\hline 13 & 20.4 & 17.1 \\
\hline 14 & 22.8 & 18.9 \\
\hline 15 & 25.1 & 20.1 \\
\hline 16 & 26.7 & 23.3 \\
\hline 17 & 29.8 & 25.6 \\
\hline 18 & 30.6 & 26.3 \\
\hline 19 & 33.0 & 27.3 \\
\hline 20 & 37.1 & 30.4 \\
\hline
\end{tabular}

The effects of adding the fuselage shells, the wind screen glass and doors are summarized in Table 4 (in the third column). As it can be seen from the results of simulations, adding shells and secondary components to the basic structure reduces the frequency considerably. For example, it is almost $59 \%$ reduction on the 7 th mode and $18 \%$ on the 20 th mode. It is well known that the shells, doors and wind screen are not contributing to the stiffness of the model as much as their total weights. The results are summarized as given in Table 5, as the full weighted model (the 2nd column). Since the exciting frequency of the rotor head is almost $6.45 \mathrm{~Hz}(387 \mathrm{rpm})$, the first harmonic of the main rotor head (regarding the three bladed main rotor) will be $19.35 \mathrm{~Hz}$. So, the mode number 17 and 18 will be critical modes and have to be considered carefully in design stage in order to prevent resonance on the structure.

Obviously by adding the non-structural masses the frequency response experienced another reduction which is strictly related to increasing the weights. The frequency range reasonably matches with the results available in literature [7]. This establishes the confidence in the baseline model developed here.

To monitor the changes of repairing the cracks on the fuselage through patching new plates, a plate is patched to the undercarriage of the helicopter with the size of $20 * 20 \mathrm{~cm}$. Obviously, the number of places which are likely to be patched and their locations (e.g. on the fuselage, tail boom, etc.) will be important. However the aim of this research is to show the ability of the $3 \mathrm{D}$ model in investigation of different structural repairs on the vibration characteristics of the helicopter. So the problem has been simplified only by considering one patched plate at the particular location. It can be seen from Table V, a patch even with the same material as its original at the undercarriage of the helicopter will decrease the natural frequencies, especially in higher modes.

This phenomenon will intensify if the number of patched places increases. It is possible to run further scenarios on the model beforehand.

Using patched plates which do not have the same material property as the original will lead to changes in the modes (19 and 20) which are close to those natural frequencies (17 and 18) that can lead to resonance of the structure and catastrophic failures. With increasing the severity of the difference in material which has been used, the impact of patched plate on the free vibration response of the system will magnify, especially when the plate has higher density compare to the original value.

\section{Conclusion}

A precise FEM model of a helicopter can provide a broad insight in the design stage of the helicopter. The results on the natural frequencies of the full structure reasonably match with the literature giving confidence in the baseline model. Thus, the model gives a comprehensive design tool for analysing the frequencies of the helicopter with differing components. The free vibration analysis done in this research shows higher natural frequencies for 
the basic frame than the full structure of the helicopter. It shows the significant effects of secondary components on structural modelling of the helicopter. Based on the FEM model and the helicopter rotor speed, modes number 17 and 18 are identified as the critical modes. These modes have to be focused on to avoid resonance. The applied repair scenario of patching a new plate (withconsidered $\pm 50 \%$ deviation from its original density) to fix undercarriage section shows effects on mode 19 and 20 which are close to the critical modes. So, it is strongly suggested to test more patched plates in different locations of the helicopter structure to monitor the changes, precisely. It is also recommended to have arranged scenarios collected during repair and maintenance period of the helicopter structure and then applied them to developed model in future research.

Table 5. Natural frequencies of the full weighted structure (2nd column), with a patched plate in different scenarios

\begin{tabular}{|c|c|c|c|c|c|c|c|c|c|c|c|c|}
\hline \multirow[b]{2}{*}{ Mode } & \multirow{2}{*}{$\begin{array}{c}\text { Freq. of } \\
\text { full } \\
\text { weighted } \\
\text { structure }\end{array}$} & \multirow{2}{*}{$\begin{array}{c}\text { Patched } \\
\text { plate with } \\
\text { original } \\
\text { material }\end{array}$} & \multicolumn{10}{|c|}{ Density scenario of the patched plate } \\
\hline & & & $+10 \%$ & $+20 \%$ & $+30 \%$ & $+40 \%$ & $+50 \%$ & $-10 \%$ & $-20 \%$ & $-30 \%$ & $-40 \%$ & $-50 \%$ \\
\hline $1,2,3,4,5,6$ & 0.0 & 0.0 & 0.00 & 0.00 & 0.00 & 0.00 & 0.00 & 0.00 & 0.00 & 0.00 & 0.00 & 0.00 \\
\hline 7 & 3.39 & 3.39 & 3.39 & 3.39 & 3.39 & 3.39 & 3.39 & 3.39 & 3.39 & 3.39 & 3.39 & 3.39 \\
\hline 8 & 3.77 & 3.77 & 3.77 & 3.77 & 3.77 & 3.77 & 3.77 & 3.77 & 3.77 & 3.77 & 3.77 & 3.77 \\
\hline 9 & 4.20 & 4.20 & 4.20 & 4.20 & 4.20 & 4.20 & 4.20 & 4.20 & 4.20 & 4.20 & 4.20 & 4.20 \\
\hline 10 & 8.29 & 8.28 & 8.28 & 8.28 & 8.28 & 8.28 & 8.28 & 8.28 & 8.28 & 8.28 & \begin{tabular}{|l|}
8.28 \\
\end{tabular} & 8.28 \\
\hline 11 & 9.00 & 8.99 & 8.99 & 8.99 & 8.99 & 8.99 & 8.99 & 8.99 & 8.99 & 8.99 & \begin{tabular}{|l|}
8.99 \\
\end{tabular} & 8.99 \\
\hline 12 & 9.40 & 9.40 & 9.40 & 9.40 & 9.40 & 9.40 & 9.40 & 9.40 & 9.40 & 9.40 & 9.40 & 9.40 \\
\hline 13 & 10.16 & 10.16 & 10.16 & 10.16 & 10.16 & 10.16 & 10.16 & 10.16 & 10.16 & 10.16 & 10.16 & 10.16 \\
\hline 14 & 13.37 & 13.37 & 13.37 & 13.37 & 13.37 & 13.37 & 13.37 & 13.37 & 13.37 & 13.37 & 13.37 & 13.37 \\
\hline 15 & 15.85 & 15.82 & 15.82 & 15.82 & 15.82 & 15.82 & 15.82 & 15.82 & 15.82 & 15.82 & 15.82 & 15.82 \\
\hline 16 & 16.91 & 16.91 & 16.91 & 16.91 & 16.91 & 16.91 & 16.91 & 16.91 & 16.19 & 16.91 & 16.91 & 16.91 \\
\hline 17 & 18.72 & 18.71 & 18.71 & 18.71 & 18.71 & 18.71 & 18.71 & 18.71 & 18.17 & 18.71 & 18.71 & 18.71 \\
\hline 18 & 20.62 & 20.61 & 20.61 & 20.61 & 20.61 & 20.61 & 20.61 & 20.61 & 20.61 & 20.61 & 20.61 & 20.61 \\
\hline 19 & 24.99 & 24.64 & 24.52 & 24.28 & 24.08 & 23.88 & 23.68 & 24.48 & 97 & 24.99 & 25.00 & 25.00 \\
\hline 20 & 25.96 & 24.96 & 24.96 & 24.93 & 24.88 & 24.80 & 24.69 & 24.95 & 25.11 & 25.30 & 25.50 & 25.70 \\
\hline
\end{tabular}

\section{References}

1. M. Giglio, A. Manes, U. Mariani, R. Molinaro, W. Matta, Helicopter fuselage crack monitoring and prognosis through on-board sensor network, Proc. of CM (2009)

2. S. Castillo-Rivera, M.Tomas-Rodriguez, Hover Flight Helicopter Modelling and Vibrations Analysis, XXXVI Jornadas de Automática, (2015)

3. O. A.Bauchau, J. Rodriguez, S. Y Chen, Coupled rotor fuselage analysis with finite motions using component mode synthesis. Journal of the American Helicopter Society, 49 (2004)

4. Tamer, V. Muscarello, P. Masarati, G. Quaranta, Y. Yaman, Helicopter vibratory loads and vibrations reduction using higher-harmonic control, 39th European Rotorcraft Forum (2014)

5. S. Stupar, A. Simonovic, M. Jovanovic, Measurement and analysis of vibrations on the helicopter structure in order to detect defects of operating elements, Scientific Technical Review, 62 (2012)

6. H. Yeo, I. Chopra, Coupled rotor/fuselage vibration analysis using detailed 3-D airframe models, Mathematical and computer modelling, 33 (2001)

7. R. Heffernan, D. Precetti, W. Johnson, NASA report: Vibration analysis of the SA349/2 Helicopter (1991).

8. G. Gmurczyk, P. Reymer, M. Kurdelski, Global FEM model of combat helicopter, Journal of Kones, 18 (2011).

9. M. S. Annett, M. A. Polanco, System-integrated finite element analysis of a full-scale helicopter crash test with deployable energy absorbers, American helicopter society 66th annual forum (2010).

10. W. A Stepniewski, Comparative Study of Soviet VS Western Helicopters.-Pt. 2: Evaluation of Weight, Maintainability and Design Aspects of Major Components, NASA (1983). 